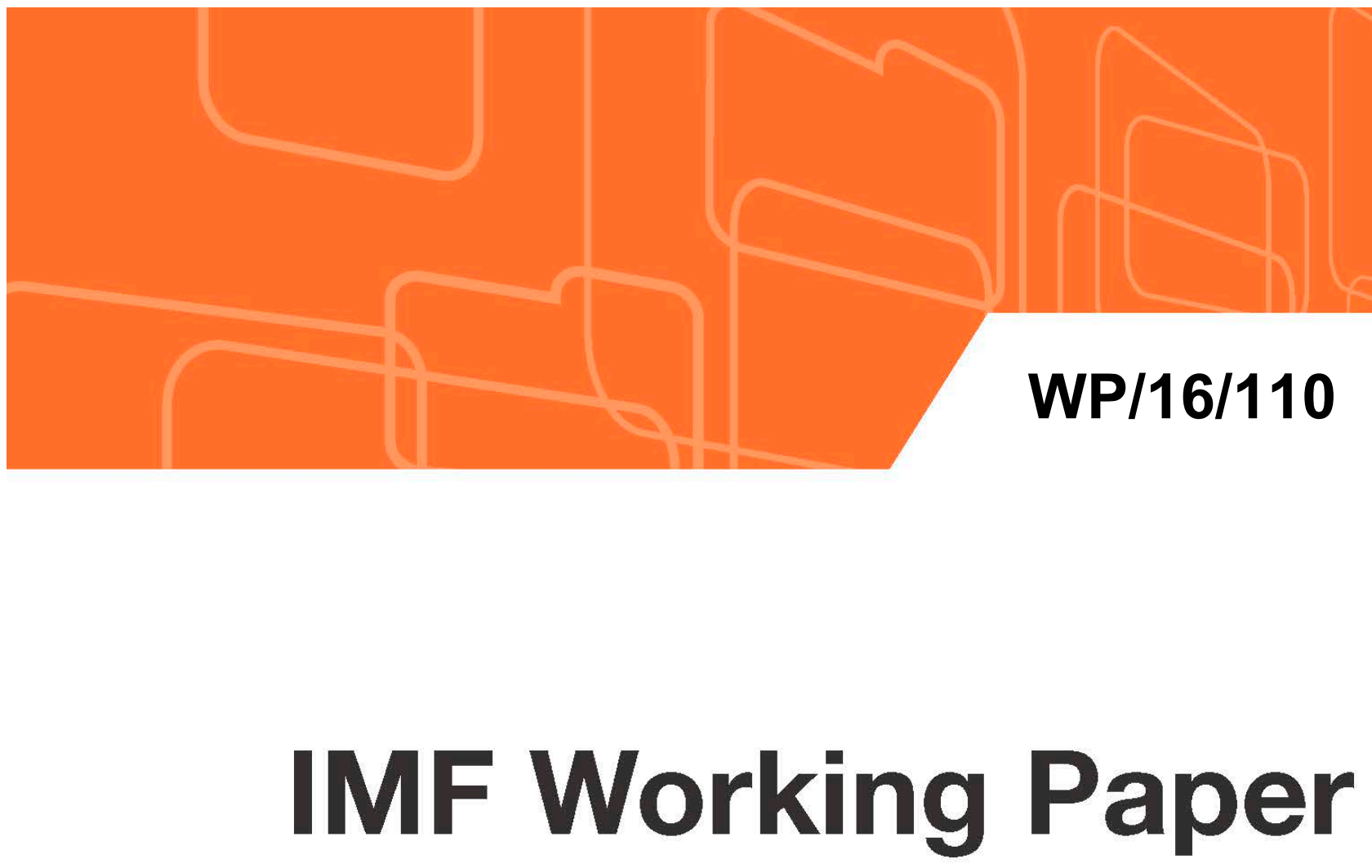

\title{
Changes in Prudential Policy Instruments-A New Cross-Country Database
}

by Eugenio Cerutti, Ricardo Correa, Elisabetta Fiorentino, and Esther Segalla

IMF Working Papers describe research in progress by the author(s) and are published to elicit comments and to encourage debate. The views expressed in IMF Working Papers are those of the author(s) and do not necessarily represent the views of the IMF, its Executive Board, or IMF management.

$\begin{array}{lllllllllllllllllllllllll}\text { I } & N & T & E & R & N & A & T & \text { I } & \text { O } & \text { N } & \text { A } & L & M & O & N & E & T & A & R & Y & F & U & N & D\end{array}$ 


\title{
IMF Working Paper
}

\author{
Research Department
}

\section{Changes in Prudential Policy Instruments-A New Cross-Country Database ${ }^{*}$}

\section{Prepared by}

\author{
Eugenio Cerutti, Ricardo Correa, Elisabetta Fiorentino, and Esther Segalla ${ }^{+}$
}

Authorized for distribution by Giovanni Dell'Ariccia

June 2016

\begin{abstract}
IMF Working Papers describe research in progress by the author(s) and are published to elicit comments and to encourage debate. The views expressed in IMF Working Papers are those of the author(s) and do not necessarily represent the views of the IMF, its Executive Board, or IMF management.
\end{abstract}

\begin{abstract}
This paper documents the features of a new database that focuses on changes in the intensity in the usage of several widely used prudential tools, taking into account both macro-prudential and micro-prudential objectives. The database coverage is broad, spanning 64 countries, and with quarterly data for the period 2000Q1 through 2014Q4. The five types of prudential instruments in the database are: capital buffers, interbank exposure limits, concentration limits, loan to value (LTV) ratio limits, and reserve requirements. A total of nine prudential tools are constructed since some useful further decompositions are presented, with capital buffers divided into four subindices: general capital requirements, real state credit specific capital buffers, consumer credit specific capital buffers, and other specific capital buffers; and with reserve requirements divided into two sub-indices: domestic currency capital requirements and foreign currency capital requirements. While general capital requirements have the most changes from the cross-country perspective, LTV ratio limits and reserve requirements have the largest number of tightening and loosening episodes. We also analyze the instruments' usage in relation to the evolution of key variables such as credit, policy rates, and house prices, finding substantial differences in the patterns of loosening or tightening of instruments in relation to business and financial cycles.
\end{abstract}

\section{JEL Classification Numbers: E43, E58, G18, G28}

Keywords: Macroprudential policies, Microprudential Policies, Financial cycles

Author's E-Mail Address: ecerutti@imf.org, ricardo.correa@frb.gov, elisabetta.fiorentino@bundesbank.de, esther.segalla@oenb.at

\footnotetext{
* This paper is part of the 2015 IBRN initiative on the domestic effects and international spillovers of prudential instruments. We would like to thank Claudia Buch, Stijn Claessens, Linda Goldberg, Claudia Jadrijevic, Steven Ongena, an anonymous referee, IBRN participants, IMF economists, and central banks and supervisory authorities for their extremely valuable feedback on the construction of the database. We also greatly appreciate the help provided by Calebe De Roure, Jacob Miller and Marcus Pramor in the construction of the database. The views expressed in this paper are solely those of the authors and should not be interpreted as reflecting the views of the Board of Governors of the Federal Reserve System, the Deutsche Bundesbank, the International Monetary Fund, and the Oesterreichische Nationalbank. The data on prudential instruments used in the paper are available on https://www.newyorkfed.org/IBRN/index.html .

+ Eugenio Cerutti is at the International Monetary Fund (700 19th Street NW, Washington, DC 20431, USA), ecerutti@imf.org, Ricardo Correa is at the Board of Governors of the Federal Reserve System (20 ${ }^{\text {th }}$ ST \& C ST, N.W., Washington, DC, 20551, United States), ricardo.correa@, frb.gov, Elisabetta Fiorentino is at the Deutsche Bundesbank (Wilhelm-Epstein-Str. 14, 60431 Frankfurt am Main, Germany) elisabetta.fiorentino@bundesbank.de, and Esther Segalla is at the Oesterreichische Nationalbank (Otto-Wagner-Platz 3, A-1090 Vienna, Austria), esther.segalla@oenb.at.
} 


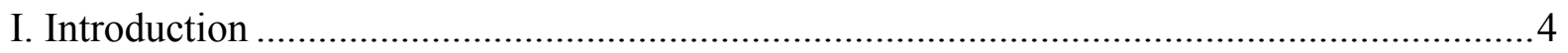

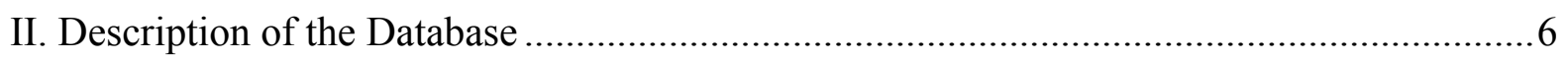

2.1 Construction of the prudential instrument indices.............................................................

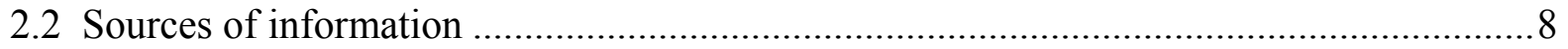

2.3 Details on specific prudential instruments..................................................................

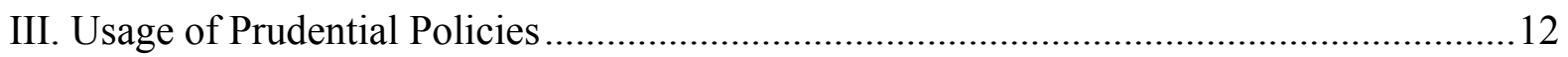

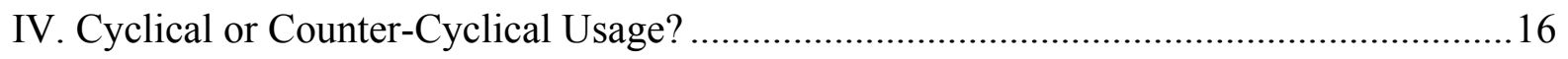

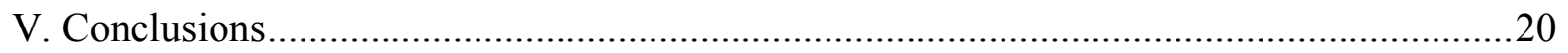

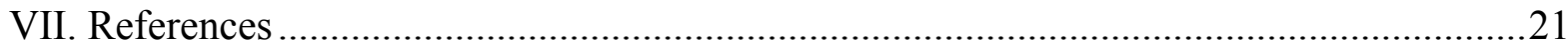

\section{TABLES}

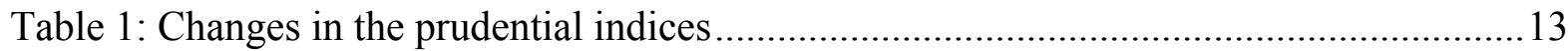

Table 2: Use of the prudential indices across countries .........................................................14

FIGURES

Figure 1: Reserve requirement ratios and cumulative index for China ..................................10

Figure 2: Changes in prudential instruments across time .......................................................15

Figure 3: Distribution of correlations between intensity changes in prudential instruments and

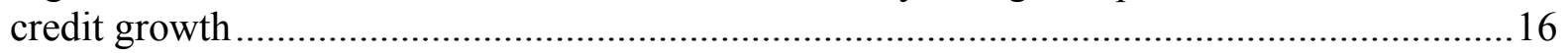
Figure 4: Distribution of correlations between intensity changes in LTV ratio limits and house

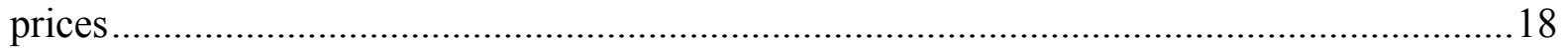
Figure 5: Distribution of correlations between intensity changes in prudential instruments and

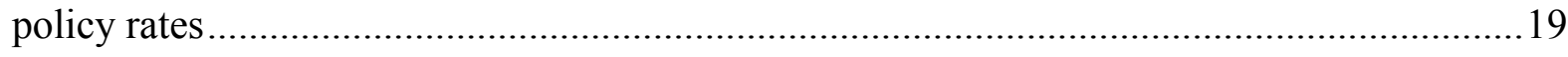

APPENDIX

List of Countries 


\section{INTRODUCTION}

Prudential instruments involving the banking system are essential in the policymaking toolkit to promote financial stability. They constitute the tools most often used to implement both microprudential and macroprudential policies. ${ }^{1}$ A full distinction between these two types of policies is blurry, and their differences are mostly based on the particular perspective used (Crockett, 2000; Borio, 2003; Claessens, 2015). Microprudential policy seeks to ensure the soundness of individual financial institutions, while macroprudential policy aims to contain systemic risks in the financial system as a whole. Independently of these often used objectives driving the specific type of policies, which often intersect, there is consensus that having a system-wide perspective is a fundamental attribute of a well-specified prudential regulatory framework (IMF, 2013). Such a prudential framework often seeks to: increase the resilience of both individual firms and the financial system to shocks (e.g., by building capital buffers); to contain the build-up of vulnerabilities over time (e.g., by reducing procyclical feedback between asset prices and credit); and to control structural vulnerabilities arising through interlinkages and the critical role of individual intermediaries in key markets that can render individual institutions "too big to fail."

Prudential instruments have been used by a large number of countries with either microprudential or macroprudential objectives, but analyzing the effectiveness of these tools and their potential unintended consequences (e.g., domestic and cross-border spillovers) is an undeveloped area at the international level, partly due to the lack of detailed and consistent cross-country information on changes - either loosening or tightening - in the use of prudential instruments. As part of the 2015 International Banking Research Network (IBRN) initiative, which examines domestic effects and international spillovers of changes in prudential instruments (see Buch and Goldberg, 2015), the main aim of this paper and its associated database is to consistently document information on the cross-country usage of key prudential instruments during the period 2000-2014, independently of the final micro or macroprudential objectives that authorities might have implicitly or explicitly had. ${ }^{2}$

In this context, our contribution to the literature is twofold. First, we compile a detailed and unique dataset of widely used prudential instruments covering the intensity in their usage over time in 64 countries at a quarterly frequency. The five types of prudential instruments at the center of the database are: capital buffers, interbank exposure limits, concentration limits, loan-to-value (LTV) ratio limits, and reserve requirements. A total of nine prudential tools are constructed since we consider some useful breakdowns of the five types of prudential

\footnotetext{
${ }^{1}$ There are other instruments in the macroprudential toolkit, such as taxes, levies, and capital flow measurements. Nevertheless, most macroprudential tools considered to date apply to the banking system, mainly given the presence of microprudential regulatory tools that are easily adaptable, the related more extensive theory, and knowledge of these tools.

${ }^{2}$ The 2015 initiative of the IBRN is a multi-study project on the domestic effects and international spillovers of prudential instruments, where teams of researchers from 15 central banks and 2 international organizations used confidential micro-banking data and more precise measures of prudential regulation, than were available to prior researchers, to test their hypotheses.
} 
instruments analyzed (capital buffers into four sub-indices: general capital requirements, real state credit related specific capital buffers, consumer credit related specific capital buffers, and other specific capital buffers; reserve requirements into two sub-indices: domestic currency capital requirements and foreign currency capital requirements). Second, we take advantage of these quarterly series and provide a cross-country view of their usage, taking also into account their correlation with key variables such as credit, policy rates, and house prices. These views provide a valuable perspective on how countries are effectively using prudential instruments through business and financial cycles.

The selection of these five types of prudential instruments was based on the need to focus on the most widely used prudential instruments across countries. Following Cerutti, Claessens, and Laeven (2015), which offers the largest coverage on the introduction of macroprudential tools within 119 countries during the period 2000-2013, we selected concentration limits, reserve requirements, LTV ratio limits, and interbank exposures limits, since they are the top four instruments in terms of usage. ${ }^{3}$ In addition, since our objective is to cover prudential instruments independent of their microprudential or macroprudential objective, we added capital buffers, a key instrument of modern bank regulation and also widely used (especially from a microprudential perspective).

The prudential database aggregates information from primary sources (e.g., central bank reports) and secondary sources (e.g., the Global Macroprudential Policy Instruments [GMPI] survey conducted by the International Monetary Fund during 2013). The sources used for each regulatory change are documented in section 2 and in the internet appendix. The resulting database provides a comprehensive, multi-country, longitudinal overview of prudential policies at quarterly frequency. Efforts to ensure the consistency of the dataset were the result of feedback received directly from country regulators on the accuracy of the policy changes recorded in the database.

Our database represents further progress in recent efforts to measure the use of prudential tools across a large number of countries (e.g., Lim et al., 2011; Zhang and Zoli, 2014; Cerutti, Claessens, and Laeven, 2015; Aysan et al., 2015). The closest to our dataset is Akinci and Olmstead-Rumsey (2015), which analyzes macroprudential policies in 57 advanced and emerging economies covering the period from 2000Q1 to 2013Q4, with tightening and easing recorded separately for seven macroprudential tools, and with a primary focus on tools applied to address housing sector developments. Compared to Akinci and Olmstead-Rumsey (2015), our database captures a broader set of instruments that impact the balance sheets of banks, such as capital and reserve requirements, which makes it more appropriate for studying the effects of prudential regulations on banking activities. In contrast,Akinci and Olmstead-Rumsey (2015) is better suited for analyzing imbalances in the

\footnotetext{
${ }^{3}$ In Cerutti, Claessens, and Laeven (2015), an instrument is being used if it is written into a law or into regulatory rules. Their analysis shows that concentration limits was used (in a least one year) in 64 percent of the 119 countries in their sample, reserve requirements in 37 percent of the countries, and LTV ratio limits and interbank exposure limits in 29 percent of the countries. The same top 4 instruments are selected following their paper definition of use frequency (the ratio of country-years using a given instrument to the total number of country-years using a macroprudential policy over the sample period 2000-2013).
} 
domestic housing sector.

More generally, beyond a larger coverage of countries or instruments compared to other datasets capturing regulatory changes, our dataset includes instruments that are used to achieve microprudential objectives, in addition to some of the macroprudential instruments covered by other databases. This is not a minor detail, because surveys of macroprudential instruments rely on the authorities' formal intentions and interpretations of the use of these instruments (i.e., whether the instrument is strictly used to comply with a macroprudential objective), which could trigger important omissions in the reporting of instruments that have been used in the past. Moreover, we also cover omissions that are triggered by implicit classifications under other objectives (e.g., monetary objectives for reserve requirements). For example, the usage of reserve requirements in China was not captured in several surveys on macroprudential instruments (e.g., GMPI) despite the fact that some specific studies such as Ma, Xiandong, and Xi (2013) highlighted their broad usage and multiple objectives, including prudential.

We find several interesting patterns when analyzing the changes in prudential indexes as documented in our database. First, even though concentration limits and interbank limits are two widely used prudential instruments, their intensities (in terms of loosening or tightening) are not often adjusted. Second, LTV ratio limits and reserve requirements (on foreign and local currency) have the largest numbers of tightening and loosening episodes. Third, instruments linked to capital buffers, concentration limits, and interbank exposures have being used to achieve structural objectives, such as creating capital buffers, and lowering risks either with a micro or macroprudential perspective. Conditional on usage, this observation is supported by the low correlation between the changes in instrument intensity and key financial variables like credit, policy rates, and houses prices. Fourth, the correlations for LTV ratio limits, and foreign and local currency reserve requirements, with credit growth signals a counter-cyclical usage by authorities in most cases. The correlations with respect to house prices are mostly not statistically significant across most countries with available data, except for a few Asian countries. Last, the correlations of LTV ratio limits and both reserve requirements with countries' policy interest rates reveal heterogeneous policy actions across countries: many statistically significant correlations indicate both complementarities and non-complementarities between these prudential instruments and policy rates.

The rest of the paper is organized as follows. Section 2 documents the construction of the prudential instruments and the sources used to code the changes in these indices. Section 3 documents the variation in the different prudential instruments over time and across countries. Section 4 analyses the usage of these prudential instruments in relation to the evolution of key variables such as credit, policy rates, and house prices. Section 5 concludes.

\section{DESCRIPTION OF THE DATABASE}

The prudential instruments database includes quarterly changes for nine prudential policy indices that have been used by policymakers with some frequency across a sample of 
64 countries during the period between 2000 and $2014 .{ }^{4}$ This section provides a general description of the construction of the indices, as well as detailed information about each specific instrument.

\subsection{Construction of the prudential instrument indices}

To construct the prudential policy indices reported in the database, we use a method to map policy changes into simple indices that has recently been used in studies focusing on the intensity of capital controls (Ahmed and Zlate, 2014; Pasricha, et al., 2015) and macroprudential policies (Akinci and Olmstead-Rumsey, 2015). Nine indices are constructed for the five types of prudential instruments covered, and the indices are presented in two ways. The first presentation of index data records the changes in a policy instrument with a 1 or -1 entry, depending on whether the prudential tool was tightened or loosen in a given quarter. The index equals 0 in those quarters when no change occurs. The entries in the database for a given instrument are coded as missing, if policymakers cannot use that policy tool. ${ }^{5}$ An example of the former case is a country that has not enacted a rule to set LTV ratio limits, the index for this instrument is coded as missing until such a rule is passed.

An advantage of this type of coding is that it can capture the intensity of a policy change, while incorporating qualitative traits from the policy that cannot be measured by a unique numerical statistic. For example, in certain circumstances, policymakers may decide to change LTV ratio limits on specific types of real estate transactions, while maintaining others unchanged. To fully measure the intensity of such a change in the instrument as a single numerical statistic would require a weighted index of all LTV ratio limits applied to the different transactions. For this purpose, one would need to have specific information on all types of real estate transactions. By recording the change with the discrete index described above, a policy change can simply be captured by entries of 1 and -1 in the index. The intensity of the change, although captured imperfectly by this index, measures the direction of the policy change.

For some policy instruments, we are able to record more precisely the intensity of the changes. This is the case for those instruments that can be summarized by a single numerical indicator. An example of these instruments is reserve requirements on local or foreign currency deposits. Although there is some variation across countries, changes in reserve requirements can be captured by a single statistic (Cordella, et al, 2014; Federico, Vegh, and Vuletin, 2014). Using that statistic, we use positive and negative integers to capture the intensity of the instrument's change relative to the starting date, which in the database is the first quarter of 2000 .

\footnotetext{
${ }^{4} \mathrm{~A}$ list of the 64 countries included in the database is reported in the appendix. Out of these 64 countries, we have limited coverage for 7 countries, which are highlighted in the appendix.

${ }^{5}$ Observations are also coded as missing for a few countries without any information for the concentration and interbank exposure limits. We also record the entries for the general capital requirements index of seven countries, listed in bold in the appendix, as missing. These type of missing values are coded differently in the database from those that reflect the lack of availability of the policy instrument.
} 
Recording the intensity of the change in the policy instrument allows us to produce a second class of index, which we call the "cumulative" index. In each quarter, the cumulative index is the sum, since the first quarter of 2000, of all changes in the policy index recorder prior to, and during, the quarter of interest. The purpose of this cumulative index is to capture the level of "tightness" ("looseness") of an instrument at a given point in time.

Although the properties of this index are appropriate for capturing the intensity of policy changes in a given country over time, they are not ideal for assessing differences in the policy stance across countries. For example, the level of an instrument may be different at the starting point in 2000 or the changes in the instruments may have different qualitative implications across countries, which may not be captured by the index. Thus, the instrument indexes should be used with caution when making cross-sectional comparisons with regards to the tightness (or looseness) of a particular instrument.

\subsection{Sources of information}

We use a combination of primary and secondary sources to record the changes in the nine policy instruments included in the database. The starting point to determine these instruments' changes is the GMPI survey (see Cerutti, Claessens, and Laeven, 2015, for a description). This survey provides a comprehensive view of the set of macroprudential policies that have been used across a large sample of 125 countries. ${ }^{6} \mathrm{We}$ also use primary information provided directly by national authorities either through the IBRN or the IMF or our searches in national authorities' webpages. We complement these data with other secondary sources like the earlier IMF dataset compiled by Lim et al. (2011) and with information drawn from other general databases that have been compiled in recent years by Akinci and Olmstead-Rumsey (2015), Kuttner and Shim (2013), and Reinhart and Sowerbutts (2015). Additionally, we also complement this information with specific secondary sources of information that apply to the different prudential instruments, as described in the internet appendix.

Lastly, one of the main contributions of the database is the participation of IBRN members in the process of constructing the database. All versions of the database were reviewed by staff from Central Banks participating in the IBRN to ensure its accuracy and completeness. For instance, they provided information on instrument changes that were not recorded in the aforementioned databases, or noted inaccuracies that were corrected. We also received valuable feedback from country representatives who filled the GMPI survey through staff at the IMF.

\footnotetext{
${ }^{6}$ Even though the GMPI survey included a question asking about the changes in the covered instruments from 2000 to 2013, the responses to these questions are to a large degree missing or incomplete, constituting one of the main challenges in our documentation not only of usage, but also intensity of usage.
} 


\subsection{Details on specific prudential instruments}

\section{General capital requirements}

The general capital requirements index is based on the regulatory changes introduced in the Basel Accords through the four revisions: I, II, II.5, and III. The index takes a value of 1 when a capital regulation is implemented or tightened and zero when no changes in capital regulations take place. We assume that the implementation of the Basel Accords never loosens the existing regulation. Therefore, the index never takes the value of -1 . The main sources of information for the implementation of the Basel II, II.5, and III agreements are the Basel Committee on Banking Supervision progress reports on members' implementation and country supervision authorities' websites. ${ }^{7}$ For those countries not covered by these publiclyavailable sources, we directly submitted inquiries to the country authorities through the IBRN or IMF.

The capital requirements index records policy changes at the point in time when the law is implemented and not when it is passed. More importantly, we code the Basel I, II.5, and III agreements as a tightening (an entry equaling 1) of capital requirements, whereas Basel II is coded as neutral (an entry of zero). The decision to record Basel II as not changing the intensity of capital requirements is based on evidence that suggests that the introduction of this agreement did not lead to a tightening nor a loosening of overall capital requirement regulations. ${ }^{8}$ As stated by the Basel Committee, the objective of Basel II regarding the overall level of minimum capital requirements was "to broadly maintain the aggregate level of minimum capital requirements, while also providing incentives to adopt the more advanced risk-sensitive approaches of the revised framework" (Basel Committee on Banking Supervision, 2006).

\section{Sector specific capital buffers}

The sector specific capital buffer index is another bank-capital based indicator that captures regulatory changes that are aimed at curtailing the growth in bank claims to specific sectors of the economy. Changes in this type of prudential instruments usually take the form of adjustments to the risk-weights of specific bank exposures, which are tightened or loosened with the financial cycle.

We separately record changes for three categories of credit depending on the borrower's type, namely: real estate credit, consumer credit, and other credit. The aggregate sector specific capital buffer index is equal to the sum of prudential instrument changes across the

\footnotetext{
7 The BIS sources are the "Progress Report on Implementation of the Basel Regulatory Framework" (http://www.bis.org/bcbs/implementation.htm) and the "FSI Survey - Basel II, 2.5 and III Implementation" (http://www.bis.org/fsi/fsiop2015.htm).

${ }^{8}$ For a detailed analysis of the quantitative impact of Basel II, see the Financial Stability Institute's report titled "Results of the fifth quantitative impact study (QIS 5)", which can be found at this link: http://www.bis.org/bcbs/qis/qis5results.pdf.
} 
different types of credit. As such, the index can take on values greater or lower than 1 or -1 in a given quarter, which would signal changes in the capital buffers for more than one sector at the same time.

\section{Reserve Requirements}

Reserve requirements have typically been used as instruments to conduct monetary policy. However, as noted by Cordella et al. (2014), these requirements have also been used as countercyclical macroprudential tools by emerging economies. The GMPI survey explicitly asked respondents whether they use this tool as a macroprudential or monetary policy tool. We rely on this information to determine whether changes in the instrument should be included in the database, which we complement with other sources if the GMPI does not report whether the country uses reserve requirements to achieve macroprudential objectives.

After we determine that reserve requirements are used in a country to satisfy prudential objectives, we proceed to collect information on the changes in these requirements over time. We separately collect information on changes in reserve requirements for deposit accounts denominated in domestic and foreign currency. The principal sources of information to determine these policy changes are central banks websites, the IMF's Annual Report on Exchange Arrangements and Exchange Restrictions (AREAER), and a database by Federico, Vegh, and Vuletin (2014).

Although reserve requirement ratios are typically reported as a number, these requirements can apply to different types of accounts. For example, within deposit accounts, there may be several subcategories, such as demand and savings accounts. Similarly, reserve requirement ratios may apply to deposits of different maturities. We use the numeric index defined earlier to capture the overall level of reserve requirements within a broad category. Given the mostly quantitative nature of this instrument, we also use numbers above or below 1 and -1 to record the intensity in the changes. As shown in Figure 1, the cumulative index that records changes in reserve requirements ratios in China tracks the contour of the level of this instrument well. This is one of the strengths of the index, as it is able to capture changes in these policies, while at the same time implicitly taking into account qualitative changes like the differentiated treatment of large, and small and medium depository institutions in mid2008 .

Figure 1: Reserve requirement ratios and cumulative index for China

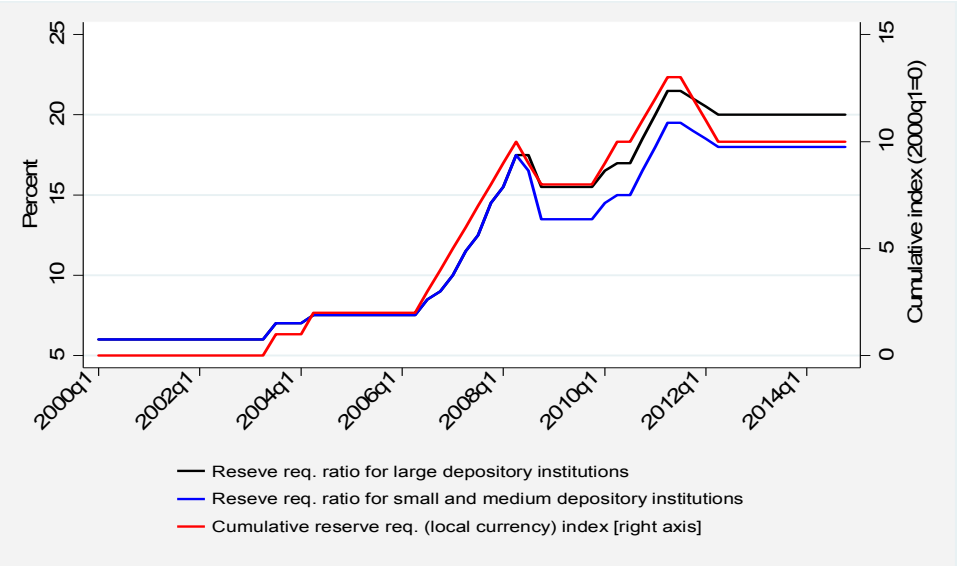




\section{Concentration Limits and Interbank Exposure Limits}

Limits on concentrated exposures and on exposures to other banks are multifaceted policies that affect claims between banks and their borrowers. As opposed to reserve requirement ratios, these limits can be changed by modifying at least five elements that characterize these exposures:

- The definition of large exposures: As defined by the Basel Committee on Banking Supervision (2014), an exposure should be classified as large if "the sum of all exposure values of a bank to a counterparty or to a group of connected counterparties... is equal to or above $10 \%$ of the bank's eligible capital base." However, there are some differences in the specific definitions across countries. For example, France characterizes large exposures as those representing $10 \%$ of eligible capital of a bank or those with a value of more than 300 million euros.

- The level of the limit: The limit on these exposures may be defined as a share of a bank's capital or in monetary terms. These exposures are weighted by the appropriate risk weights.

- Differentiation across counterparties: Weights on exposures may depend on the "riskiness" of the counterparty and the duration of the claims.

- Aggregate limits: Banks may also face aggregate concentration limits, totaled across all large exposures, which should not exceed a threshold expressed as a share of eligible capital.

- Sectors and assets that are covered by the regulation: The regulation may cover the exposures of depository institutions, or it may apply to a larger group, incorporating those of non-bank financial institutions. On the counterparty side, some sectors may be exempted from banks' concentration limits. In other cases, the definition of qualified assets that are counted towards exposures limits may also change over time (e.g., interbank exposures).

These layers that encompass the concentration and interbank exposure limits require a careful assessment of the changes in the characteristics of these regulatory requirements over time. We use our index to record these changes using information from the GMPI survey. In the process, we rely on three assumptions to code the changes. First, if multiple changes to the characteristics defined above are implemented, we determine whether, on net, the policy tightened or loosened these exposures limits. Second, if the rules determining the concentration limits, including interbank exposures, are changed in a given quarter, we only code the change for concentration limits and not for interbank exposures. If the changes mostly apply to interbank exposures, we only code a change for this index. Last, in cases when the authorities do not specify the exact quarter, within a year, when the policy changes were implemented, we use the first quarter of that year as the date of implementation. 


\section{Loan to Value Ratio Limits}

LTV ratio limits, or caps, are restrictions on the maximum amount that an individual or firm can borrow against their collateral. The most common form of LTV caps is applied to real estate transactions. In this particular case, authorities may limit the amount that an individual can purchase against the value of the property. The instrument is said to affect the demand for credit, as it applies to any transactions covered by the policy regardless of the type of lender.

In our index, we record changes in LTV ratio limits that affect real estate transactions. Changes in banks' risk weights associated with LTV ratios are not considered since they do not necessarily constrain the maximum borrowing capacity for borrowers. Nevertheless, two additional types of changes in maximum LTV ratio limits are taken into account: 1) changes related to the maximum amount insured in real estate transactions in Canada and Hong Kong; and 2) Changes in LTV regulations related to the maximum LTV allowed in covered bonds (Denmark and Finland). In those cases, although the regulation does not directly target the characteristics of all the loans, the impact is broadly similar (e.g., covered bonds are the main source of mortgage funding in Nordic countries).

As it is the case with reserve requirements, changes in LTV caps can be broadly tracked over time by following the evolution of this numeric variable. However, those changes can also affect subsamples of the universe of mortgages, such as first residential purchases or mortgages on properties that fall in specific price ranges. For cases in which LTVs are tightened for specific types or transactions and loosened for others, we assess whether, on net, the policy change falls in one category or the other and code it accordingly.

\section{Usage of Prudential Policies}

This section presents information on the changes recorded in the indices for the policy instruments described before, and for their subcomponents. The database contains information for five types of prudential instruments and 64 countries. For two of the instruments, we also calculate subcomponents. In the case of the sector specific capital buffers, we calculate indices for buffers that apply separately to real estate loans, consumer loans, and other loans. Similarly, for reserve requirements, we calculate separate indices for policy changes that apply to accounts denominated in foreign currency and domestic currency. Adding these sub-components, the total number of prudential indices increases to nine.

Table 1 presents information on the number of quarterly episodes recorded in each of the nine indices. As expected, in any given quarter most indexes do not change, which explains the large mass of observation at the value zero. LTV ratio limits and reserve requirements (on foreign and local currency) have the largest numbers of tightening and loosening episodes. The index on general capital requirements differs from all the others because it only encompasses tightenings. These one-sided changes are explained by the way the index is coded, which only incorporates information on the implementation of the Basel Accords (these regulatory changes are coded as neutral or tightenings). 


\section{Table 1: Changes in the prudential indices}

This table presents the frequencies of non-missing observations in the prudential database tabulated by instrument and the value of the index in any given quarter. SSCB stands for sector specific capital buffer and RR for reserve requirements. We use all subcomponents of the indices, including the SSCBs for real estate, consumer, and other loans, and RRs split between those applied to local and foreign currency deposit accounts. The value 0 is coded when a given policy instrument is not changed in a quarter. Tightening episodes are recorded with positive values in the index and loosening episodes with negative values.

\begin{tabular}{crrrrrrrrr}
\hline Value & $\begin{array}{r}\text { SSCB real } \\
\text { estate } \\
\text { loans }\end{array}$ & $\begin{array}{r}\text { Sonsumer } \\
\text { loans }\end{array}$ & $\begin{array}{r}\text { SSCB other } \\
\text { loans }\end{array}$ & $\begin{array}{r}\text { Concentration } \\
\text { limits }\end{array}$ & $\begin{array}{r}\text { Interbank } \\
\text { exposures }\end{array}$ & $\begin{array}{r}\text { RR foreign } \\
\text { currency }\end{array}$ & $\begin{array}{r}\text { RR } \\
\text { local } \\
\text { currency }\end{array}$ & $\begin{array}{r}\text { Loan to } \\
\text { value ratio } \\
\text { limits }\end{array}$ & $\begin{array}{r}\text { General } \\
\text { capital } \\
\text { reqs. }\end{array}$ \\
\hline \hline-3 & 0 & 0 & 0 & 0 & 0 & 2 & 1 & 0 \\
-2 & 0 & 0 & 1 & 0 & 0 & 8 & 8 & 0 \\
-1 & 15 & 3 & 4 & 2 & 1 & 41 & 157 & 25 & 0 \\
\hline 0 & 3787 & 3828 & 3819 & 2023 & 1100 & 3699 & 3543 & 1201 & 3320 \\
\hline 1 & 38 & 9 & 14 & 32 & 24 & 85 & 126 & 72 & 100 \\
\hline 2 & 0 & 0 & 2 & 0 & 0 & 3 & 2 & 0 \\
\hline 3 & 0 & 0 & 0 & 0 & 0 & 1 & 0 & 0 \\
\hline 4 & 0 & 0 & 0 & 0 & 0 & 0 & 0 & 0 \\
\hline 5 & 0 & 0 & 0 & 0 & 0 & 1 & 1 & 0 \\
\hline Total & 3840 & 3840 & 3840 & 2057 & 1125 & 3840 & 3838 & 0 \\
\hline
\end{tabular}


Note that the total number of episodes varies across instruments. As explained in the previous section, instruments that are not available to policymakers due to the absence of legislation that authorizes their use are coded as missing in the database. For some countries, instruments that are introduced during the sample period are coded as of the date the legislation to authorize them is passed. In these cases, if the introduction of the instrument is considered a tightening of the policy stance, it is coded as one in the index. There are other instances when the introduction of the instrument does not affect the policy stance, such as introducing reserve requirements and setting them at zero, which are coded as zero in the index.

The information in Table 2 reports the number of countries with policy changes in the sample period, as opposed to the number of total episodes. As expected, most countries made changes to the general capital requirements, as they adopted different versions of the Basel Accords in the past 15 years. Similarly, reserve requirements on local currency accounts and LTV ratio limits are instrument broadly used by countries in the sample, but in contrast to capital requirements, these policy tools are both tightened and loosened by many countries in the sample. On the other side of the spectrum, we find that interbank exposures are only modified by one-fifth of the sample, and most of these changes involve a tightening.

\section{Table 2: Use of the prudential indices across countries}

This table reports information on the number of countries with policy changes for each instrument. The database contains a total of 64 countries. SSCB stands for sector specific capital buffer and RR for reserve requirements. We use all subcomponents of the indices, including the SSCBs for real estate, consumer, and other loans, and RRs split between those applied to local and foreign currency deposit accounts. The last column shows the number of countries with access to a given instrument at any point in time during the sample period or those countries for which we have any information.

\begin{tabular}{lrrrr}
\hline & $\begin{array}{r}\text { Distinct } \\
\text { countries with } \\
\text { instrument } \\
\text { changes }\end{array}$ & $\begin{array}{r}\text { Countries } \\
\text { with } \\
\text { tightening } \\
\text { episodes }\end{array}$ & $\begin{array}{r}\text { Countries } \\
\text { with } \\
\text { loosening } \\
\text { episodes }\end{array}$ & $\begin{array}{r}\text { Countries } \\
\text { with }\end{array}$ \\
\hline \hline $\begin{array}{l}\text { SSCB Real estate } \\
\text { loans }\end{array}$ & 22 & 20 & 9 & 64 \\
$\begin{array}{l}\text { SSCB Consumer } \\
\text { loans }\end{array}$ & 9 & 7 & 3 & 64 \\
SSCB other loans & 12 & 11 & 3 & 64 \\
$\begin{array}{l}\text { Concentration } \\
\text { limits }\end{array}$ & 22 & 21 & 2 & 36 \\
$\begin{array}{l}\text { Interbank } \\
\text { exposures }\end{array}$ & 14 & 13 & 1 & 22 \\
RR foreign currency & 21 & 20 & 17 & 64 \\
RR local currency & 46 & 29 & 44 & 64 \\
\hline $\begin{array}{l}\text { Loan to value ratio } \\
\text { limits }\end{array}$ & 36 & 33 & 14 & 38 \\
$\begin{array}{l}\text { General capital } \\
\text { requirements }\end{array}$ & & & & \\
\hline
\end{tabular}


As shown in these tables, the usage of prudential instruments varies notably across the different types, both in the frequency of changes and the direction of these changes. The use of prudential instruments also changes markedly across the sample period. Figure 2 presents information on the number of countries tightening or loosening three selected prudential policies in every quarter over the sample period. We focus on capital requirements, reserve requirements on local currency deposits, and LTV ratio limits, some of the indexes with more variation or wider usage across countries. As noted previously, capital requirements are only shown to be tightened during the sample period (Panel A), which is explained by the definition of the index. More importantly, those tightenings are clustered after the global financial crisis, as regulators implemented the new requirements embedded in the Basel II.5 and III Accords. In contrast, reserve requirements (Panel B) and LTV ratio limits (Panel C) exhibit changes throughout the sample period, with both tightenings and loosenings. In the case of reserve requirements, there are two important loosening periods that coincided with the global financial crisis and the European sovereign debt crisis. LTV ratio limits were largely tightened after the global financial crisis, perhaps as a result of loose monetary policies in several countries.

Figure 2: Changes in prudential instruments across time
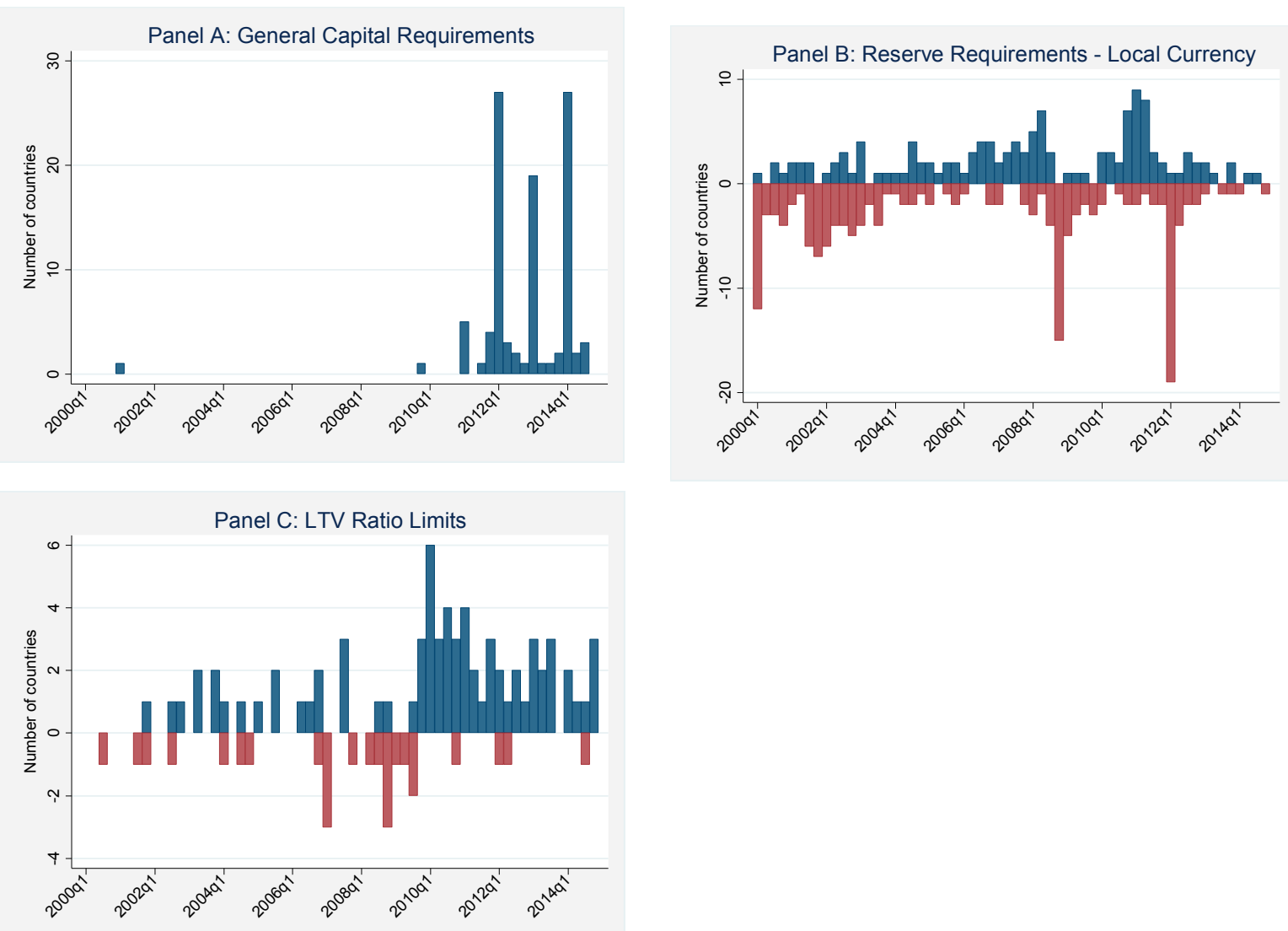
These patterns prompt several questions, especially about the reaction functions of regulators and supervisors to financial stability vulnerabilities and the use of prudential policies. Some instruments appear to be used more frequently and co-move with the financial cycle, while others are changed less often and perhaps as a reaction to financial crises. We explore these issues in the next section.

\section{Cyclical or Counter-Cyclical Usage?}

This section analyzes whether changes in the usage of prudential instruments in each country are correlated with the evolution of credit growth, house prices, and policy rates. These correlations cannot fully reveal the underlying microprudential or macroprudential emphasis used by the authorities (which could change over time), but they offer an overview of the cyclicality of prudential instruments with respect to, for example, bank credit or house prices.

In principle, if a prudential instrument is used with a macroprudential intent, then, to some degree, we would expect a positive correlation between the intensity of this instrument and credit growth, indicating a counter-cyclical usage (e.g., tightening during high growth periods and loosening during low credit growth periods). In addition, the correlation of prudential instruments with respect to the policy rate of each country offers some clues as to whether the usage of these financial stability tools has been complementary to the monetary policy objectives, as captured by the evolution of the policy rate.

\section{Figure 3: Distribution of correlations between intensity changes in prudential instruments and real credit growth}

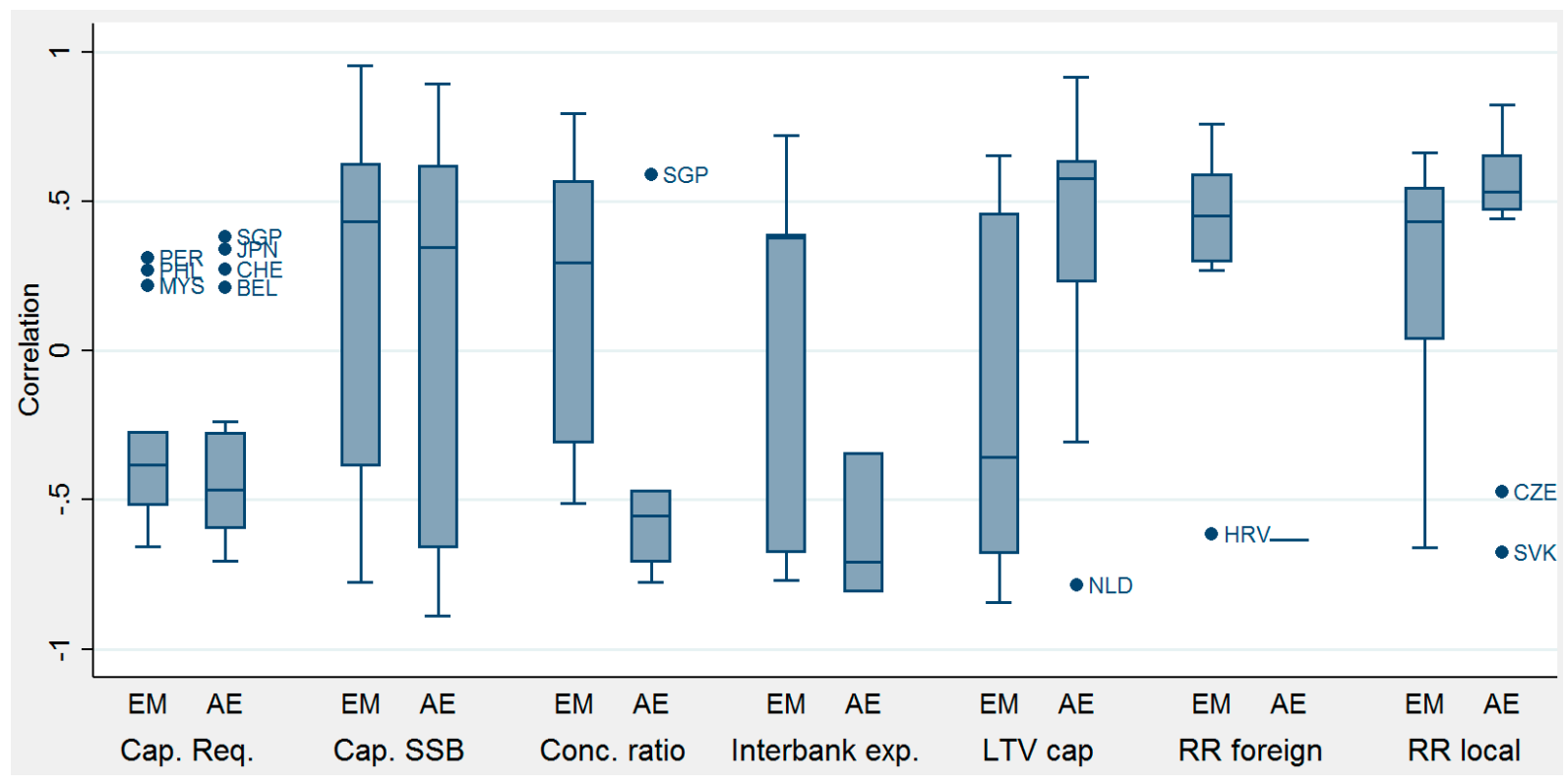

Note: Only statistically significant correlations at the 10 percent level or less are plotted.

Figure 3 shows the distribution of the statistically significant correlations between the usage of prudential instruments and real credit growth in each country. 
${ }^{9}$ These correlations are calculated based on the cumulative index of seven prudential indexes presented in the previous sections (with the three sector specific capital buffers presented as an aggregate) and real credit growth (annualized, using the most recent 4 quarters, and deflated using CPI inflation) from series produced by the Bank for International Settlements (BIS) and the IMF International Financial Statistics (IFS). ${ }^{10}$ Countries that register some fluctuation in the usage of prudential instruments over time are the only ones with correlations, so the number of correlations plotted varies across instruments. In the case of capital requirements (Cap. Req.), it is possible to calculate correlations with credit growth for 51 countries, of which 33 are statistically significant. Most of the distribution of these statistically significant correlations is clearly on the negative side (especially the distribution within the $25^{\text {th }}$ and $75^{\text {th }}$ percentiles that is captured by the boxes in the standard box plot figure). This is driven by the fact that capital requirements are not frequently changed, and the timing of changes are linked with the implementation of Basel reforms that often happen after crises or financial turmoil, coinciding with slowdowns in credit growth. The distribution of the correlations is more broadly distributed in the case of the sector specific capital buffer (Cap. SSB) than the general capital requirements (16 statistically significant correlations out of 25 available correlations), with the median being slightly above zero for both EM and AE groupings. Despite being among the most widely used instruments, changes in the intensity of usage in the concentration (Conc. ratio) and interbank exposure (Interbank exp.) limits do not show many significant correlations with the evolution of credit growth. This result is not explained by the correlations being insignificant, but by the fact that the intensity in the usage of these two instruments does not change for most countries (14 statistically significant correlations out of 18 calculated for concentration limits, and 8 statistically significant out of 11 calculated for interbank exposures limits). Moreover, most of these statistically significant correlations are for EMs, and the distribution of correlations are broadly across positive and negative values. Therefore, this evidence suggests that instruments linked to capital buffers, concentration limits, and interbank exposure limits are used with more structural objectives in mind (e.g., creating capital buffers, and lowering risks either with a micro or macroprudential perspective), instead of business or credit cycle considerations.

In contrast, the correlations for the LTV ratio limits (LTV cap) and both foreign (RR foreign) and local currency (RR local) reserve requirements with credit growth signals a countercyclical usage in most cases. The correlations of the local currency reserve requirement index (26 statistically significant correlations out of 39 calculated) are positive for both emerging markets and advanced economies. With the exception of Argentina, there are 9 emerging markets (Hungary, Croatia, Ukraine, Romania, Philippines, Lithuania, Peru, Brazil, and Turkey) with significant positive correlations. This results is similar for the index of foreign currency reserve requirements in emerging markets ( 8 statistically significant correlations out of 14 calculated; these countries are Romania, Argentina, Peru, Chile, Russia, Colombia, Brazil, and Croatia is an outlier on the negative side). These results are in line with those presented in the related literature. For example, Federico, Vegh, and Vuletin (2014) find a

\footnotetext{
${ }^{9}$ Correlations are similar if we use nominal credit growth instead of real credit growth

${ }^{10}$ Results are broken down into Emerging Markets (EM) and Advanced Economies (AE), following the IMF October 2015 World Economic Outlook (WEO) classification.
} 
positive correlation between the evolution of reserve requirements and countries' real GDP growth. Although not expected, there are 14 advanced economies with local currency reserve requirements that exhibit positive and significant correlations (such as, Italy, Spain, Portugal, Greece, Singapore, Netherlands, Slovenia, France, etc.). ${ }^{11}$ Foreign currency reserve requirements appear to be irrelevant in advanced economies, with only 3 calculated correlations, of which only one (Slovakia) is statistically significant.

For the correlations between LTV ratio limits and credit growth (there are 17 statistically significant correlations out of 21 calculated), we find evidence that some advanced economies have used this instrument more counter-cyclically. Several countries have positive correlations with respect to credit growth (Spain, Norway, Denmark, Singapore, Iceland, Luxembourg, Hong Kong, and Canada), with the only exceptions being Korea and the Netherlands. As highlighted in the literature (Cerutti, Claessens, and Laeven, 2015), the effect of LTV ratio limits on house prices is not clearly specified on average across countries. We corroborate this finding by showing in Figure 4 that the statistically significant correlations between LTV ratio limits and house prices are above and below zero in similar proportions. ${ }^{12}$

\section{Figure 4: Distribution of correlations between intensity changes} in LTV ratio limits and house prices

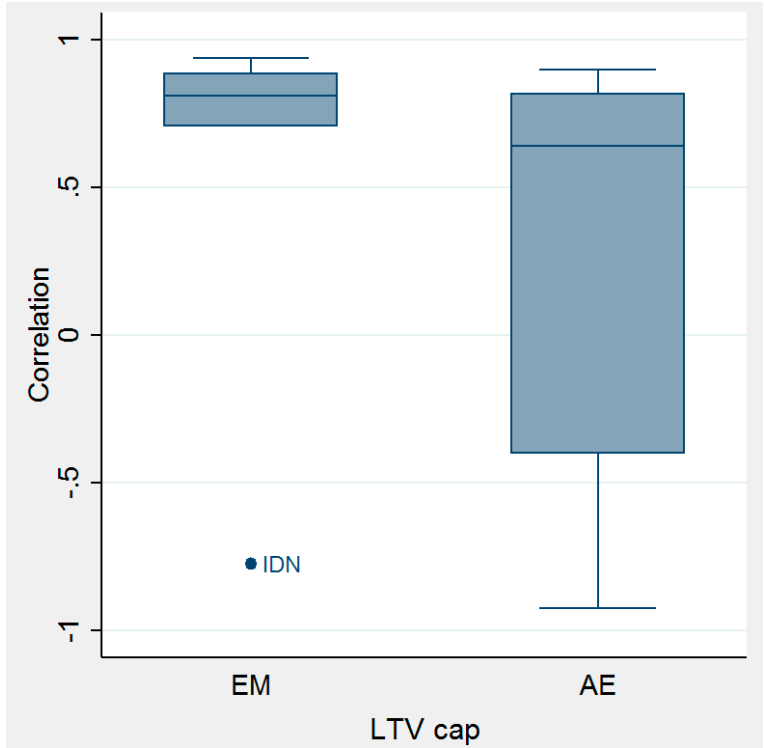

Note: Only statistically significant correlations at the 10 percent level or less are plotted.

\footnotetext{
${ }^{11}$ For euro-area countries, reserve requirements ratios are determined by the European Central Bank.

${ }^{12}$ The positive significant correlations between LTV ratio limits and house prices are mostly from Asia (e.g., Hong Kong, South Korea, Malaysia, and India). This correlation captures the effect of lending standards on house prices, and is supported by some studies (e.g., Igan and Kang 2011; International Monetary Fund, 2011; Akinci and Olmstead-Rumsey, 2015; Cerutti, Dagher, and Dell'Ariccia, 2015) that have found a positive relationship between LTV limits and house price increases over time. Other studies like Vandenbussche, Vogel, and Detragiache (2015), which focuses on Eastern Europe, find that other instrument, such as capital and nonstandard liquidity measures had a larger impact on house prices.
} 
The correlations of both LTV ratio limits and reserve requirement with countries' policy interest rates are also revealing and are shown in Figure $5 .{ }^{13}$ In the case of LTV caps, unlike the correlations with credit growth, there are advanced economies with statistically significant positive correlations (Denmark, Luxembourg, and Iceland), as well as another group with statistically significant negative correlations (Singapore, Hong Kong, and Canada). The median is around zero. We find a similar result for three emerging economies.

These findings suggest that LTV caps are used in several countries together with higher policy rates to achieve, perhaps, complementary objectives. But this pattern does not apply in all countries, as shown by some statistically significant negative correlations. In the case of reserve requirements, many emerging market economies appear to use this instrument, especially for local currency accounts, as a counter-cyclical tool to supports the monetary policy stance beyond the use of policy rates (for example, India, Argentina, Philippines, China, and Bulgaria have negative and significant correlations between reserve requirements and policy rates). However, we find the opposite pattern in a smaller group of countries, since Romania, Poland, and Lithuania display statistically significant positive correlations. Among advanced economies, changes in local currency reserve requirements are positively correlated with policy rates in 10 countries (all members of the euro area), showing that in most cases, changes in local currency reserve requirements and policy rates were used as complementary policies.

\section{Figure 5: Distribution of correlations between intensity changes in prudential instruments and policy rates}

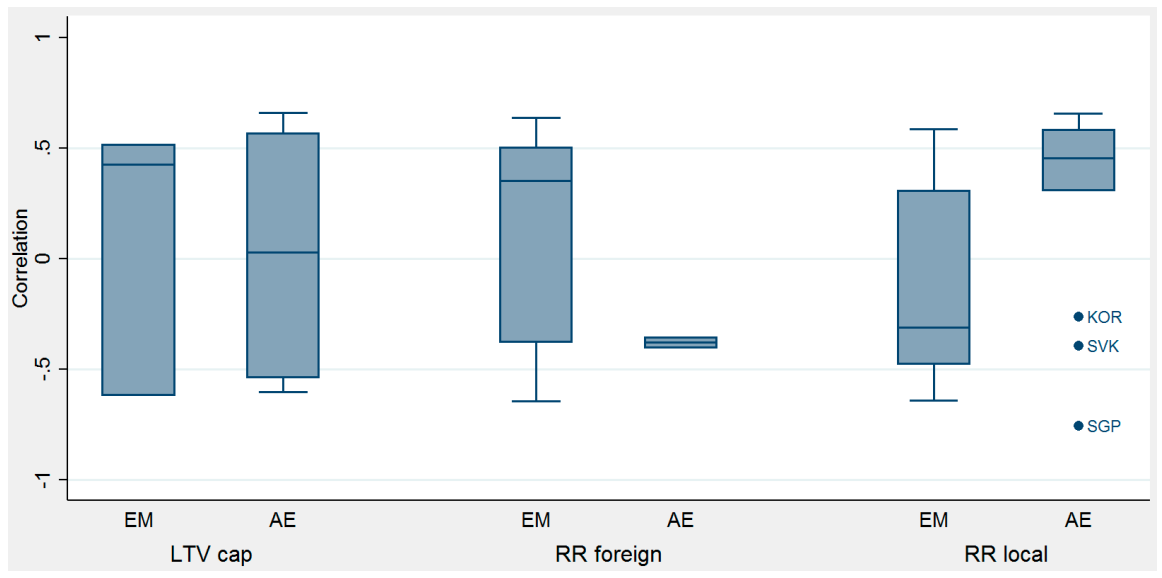

Note: Only statistically significant correlations at 10 percent or less are plotted.

\footnotetext{
${ }^{13}$ The correlations (not reported) between policy rates and the intensity of usage of capital buffers, concentration limits, and interbank exposures limits are in line with the correlations with credit growth. The changes in the usage intensity of these instruments is not related with the monetary policy stance.
} 


\section{Conclusions}

We have compiled and documented a unique dataset measuring changes in the intensity of use for nine widely used prudential tools, covering a large sample of 64 countries over the period between 2000Q1 and 2014Q4. We find that LTV caps and reserve requirements (on foreign and local currency) have the largest number of tightening and loosening episodes, despite not being the most implemented prudential instruments across countries. We also provide evidence related to the correlations between changes in prudential instruments and key financial variables such as credit, policy rates, and house prices. Changes in capital buffers, concentration limits, and interbank exposures are aimed at achieving more structural objectives, such as enhancing the resilience of the banking sector, and lowering risks either with a micro or macroprudential perspective. In contrast, we show that the use of LTV ratio limits and foreign and local currency reserve requirements appear more consistent with counter-cyclical policy objectives in most cases, but with some important heterogeneity across countries. Lastly, some of our tests indicate complementary and non-complementary interactions between a few of the prudential policy instruments and monetary policy rates.

As part of the initiative of the IBRN on cross-border prudential policy spillovers, which consisted of a multi-country and international organization study project, the dataset documented in this paper makes a clear contribution. While this database is used across all of the studies of that initiative, and helps inform the analysis of the effectiveness of prudential instruments and their potential unintended consequences at the international level, the database has much broader relevance. Given the unique nature of the dataset, it will further provide a service to future analyses in the research and policy communities on the use and the effectiveness of micro- and macro-prudential policies, towards either controlling credit growth or increasing the resilience of the financial sector. 


\section{REFERENCES}

Akinci, Ozge and Jane Olmstead-Rumsey. 2015. "How Effective are Macroprudential Policies? An Empirical Investigation," Federal Reserve Board International Finance Discussion Papers 2015-1136 (May).

Ahmed, Shaghil and Andrei Zlate, 2014. "Capital Flows to Emerging Market Economies; A Brave New World?” Journal of International Money and Finance, 1-28.

Aysan, Ahmet Faruk, Salih Fendoğlu, Mustafa Kılınç and Sümeyye Y1ldız, 2015. "Credit Cycles and Capital Flows: Effectiveness of Macroprudential Policy Framework in Emerging Countries." Mimeo, Central Bank of Turkey.

Basel Committee on Banking Supervision, 2006. "International Convergence of Capital Measurement and Capital Standards: A Revised Framework Comprehensive Version," June 2006. http://www.bis.org/publ/bcbs128.pdf

Basel Committee on Banking Supervision, 2014. "Supervisory Framework for Measuring and Controlling Large Exposures,” April 2014. http://www.bis.org/publ/bcbs283.pdf

Borio, Claudio, 2003. "Towards a Macroprudential Framework for Financial Supervision and Regulation?” BIS Working Paper 128 (February).

Buch, Claudia, and Linda Goldberg, 2015. "Cross-Border Prudential Policy Spillovers: How Much? How Important? Evidence from the International Banking Research Network."

Cerutti, Eugenio, Stijn Claessens, and Luc Laeven, 2015. "The Use and Effectiveness of Macroprudential Policies: New Evidence," forthcoming, Journal of Financial Stability

Cerutti, Eugenio, Jihad Dagher, and Giovanni Dell'Ariccia, 2015. "Housing Finance and Real-Estate Booms: A Cross-Country Perspective,” IMF Staff Discussion Note 15/12.

Claessens, Stijn, 2015. "An Overview of Macroprudential Policy Tools," Annual Review of Financial Economics, 10.1-10.26

Cordella, Tito, Pablo Federico, Carlos Vegh, and Guillermo Vuletin, 2014. "Reserve requirements in the brave macroprudential world," World Bank Policy Research Working Paper No. WPS6793 (February).

Crockett, A., 2000. "Marrying the Micro- and Macro-prudential Dimensions of Financial Stability," Eleventh International Conference of Banking Supervisors, BIS Speeches, 21 September. 
Federico, Pablo, Carlos Vegh, and Guillermo Vuletin, 2014. "Reserve Requirement Policy over the Business Cycle," NBER Working Paper No 20612.

Igan, Deniz, and Heedon Kang, 2011. "Do Loan-to-Value and Debt-to-Income Limits Work? Evidence from Korea," IMF Working Paper No. 11/297.

International Monetary Fund, 2011. "Housing Finance and Financial Stability-Back to Basics?" Global Financial Stability Report, Chapter 3, April, pp. 111-57.

_ 2013. "Key Aspects of Macroprudential Policy," IMF Policy Paper, June (Washington: International Monetary Fund).

Kuttner, Kenneth N. and Ilhyock Shim, 2013. "Can non-interest rate policies stabilise housing markets? Evidence from a panel of 57 economies,” BIS Working Papers No 433.

Lim, Cheng H., Francesco Columba, Alejo Costa, Piyabha Kongsamut, Akira Otani, Mustafa Saiyid, Torsten Wezel, Xiaoyong Wu, 2011. "Macroprudential Policy: What Instruments and How Are They Used? Lessons from Country Experiences", IMF Working Paper 11/238.

Ma, Guonan, Yan Xiandong, and Liu Xi, 2013. "China's evolving reserve requirements," Journal of Chinese Economic and Business Studies 11(2), 117-137.

Pasricha, Gurnain, Matteo Falagiarda, Martin Bijsterbosch, and Joshua Aizenman, 2015. "Domestic and Multilateral Effects of Capital Controls in Emerging Markets," National Bureau of Economic Research Working Paper Series No. 20822.

Reinhart, Dennis and Rhiannon Sowerbutts, 2015. "Regulatory arbitrage in action: evidence from banking flows and macroprudential policy," Bank of England Staff Working Paper No. 546 (September).

Vandenbussche, Jerome, Ursula Vogel, and Enrica Detragiache, 2015. "Macroprudential Policies and Housing Prices:A New Database and Empirical Evidence for Central, Eastern, and Southeastern Europe," Journal of Money, Credit and Banking 47(1), 343-377.

Zhang, Longmei and Edda Zoli, 2014. "Leaning Against the Wind: Macroprudential Policy in Asia," IMF Working Paper 
APPENDIX: List OF COUNTRIES

\begin{tabular}{|l|l|l|l|}
\hline Argentina & Germany & Malaysia & Singapore \\
\hline Australia & Greece & Malta & Slovak Republic \\
\hline Austria & Hong Kong & Mexico & Slovenia \\
\hline Belgium & Hungary & Mongolia & South Africa \\
\hline Brazil & Iceland & Netherlands & South Korea \\
\hline Bulgaria & India & New Zealand & Spain \\
\hline Canada & Indonesia & Nigeria & Sweden \\
\hline Chile & Ireland & Norway & Switzerland \\
\hline China & Israel & Peru & Taiwan \\
\hline Colombia & Italy & Philippines & Thailand \\
\hline Croatia & Japan & Poland & Turkey \\
\hline Czech Republic & Kuwait & Portugal & Ukraine \\
\hline Denmark & Latvia & Romania & United Kingdom \\
\hline Estonia & Lebanon & Russian Federation & United States \\
\hline Finland & Lithuania & Saudi Arabia & Uruguay \\
\hline France & Luxembourg & Serbia & Vietnam \\
\hline
\end{tabular}

Note: Countries with limited information in bold font. 